\title{
Neural substrates associated with humor processing
}

\author{
Jihye Noh ${ }^{1}$, Ji-woo Seok ${ }^{2}$, Suk-Hee Kim ${ }^{3}$, Chaejoon Cheong ${ }^{1}$ and Jin-Hun Sohn ${ }^{2 *}$
}

\begin{abstract}
Background: Humor is composed of a cognitive element related to the detection of humor and an affective element related to the appreciation of humor. To investigate activated areas of the brain related to the two components of humor and to identify neural substrates associated with the degree of humor intensity, 13 participants were scanned while watching cartoons.

Findings: While watching humorous scenes, various areas of the brain were activated, including (1) the inferior gyrus, an area involved in reconciling ambiguous semantic content with stored knowledge, and (2) the temporal gyrus and fusiform gyrus, brain regions associated with the feeling of mirth. Further, humor intensity was positively correlated with BOLD signal magnitude in the nucleus accumbens, a region known to be involved in psychologically and psychopharmacologically driven rewards.
\end{abstract}

Conclusions: Our findings demonstrate a two-component neural circuit model of humor processing and a key region important in pleasurable feelings accompanied by humor.

Keywords: Emotion; Humor; Detection; Appreciation; Event-related fMRI

\section{Findings}

Humor plays a central and unique role in human life. Without humor, life would undeniably be less exhilarating. Humor provides an effective means of communicating ideas, attracting partners, boosting mood, and even coping in times of trauma and stress (Brownell and Gardner 1988; Dixon 1980; Garilovic et al. 2003; Martin 2001; Mobbs et al. 2003; Neuhoff and Schaefer 2002; Nezlek and Derks 2001).

Humor involves both cognitive and affective elements (Gardner et al. 1975). The cognitive element refers to 'getting the joke' which includes moments during which the perceiver attempts to comprehend disparities between a punch line and prior experience (Brownell et al. 1983). The affective element refers to 'enjoying a joke'; these are moments during which the perceiver experiences pure visceral, emotional responses depending on the hilarity of the experience (Shammi and Stuss 2003).

\footnotetext{
* Correspondence: jhsohn@cun.ac.kr

${ }^{2}$ Department of Psychology, Brain Research Institute, Chungnam National University, Daejeon, South Korea

Full list of author information is available at the end of the article
}

Studies have been conducted to identify biological neural systems related to humor. Gardner et al. (1975) examined patients with brain injury. They found that the left hemisphere of the brain is related to the integration of information that is required for understanding humor and that the right hemisphere is associated with the emotional processing of humor. In another study, patients with an injury in the right hemisphere showed a low physical reaction and emotional response to humor (Shammi and Stuss 1999).

Studies comparing activated areas of the brain responsible for the affective element and the cognitive element have also been conducted. Moran et al. (2004) examined a brain region that is activated during humor detection (cognitive element) and humor appreciation (affective element). The inferior frontal gyrus and posterior middle temporal gyrus were found to be activated during humor detection condition, while the insula and amygdala were activated during humor appreciation condition.

While numerous studies have focused on block-designed functional magnetic resonance imaging (fMRI) related to humor, few studies have explored event-related fMRI. Whether emotion-inducing stimuli should be presented in a block-designed paradigm or event-related paradigm

\section{定 Springer}


during fMRI remains controversial. Block-designed paradigms are often used because of their easy implementation and because randomization, jittering, and spacing of different stimulus categories is not necessary (Josephs et al. 1997). In blocked designs, stimulus presentation is lengthened and consecutive stimuli in a block are predictable (Zarahn et al. 1997). Prolonged exposure of stimuli may decrease emotional involvement and hence alter underlying brain activation. In emotion research, presentation duration is particularly important, not only from a methodological point of view but also in respect of differences in information processing (Buhler et al. 2008). Event-related designs are superior in terms of rapid estimation of the hemodynamic response function to a short stimulus and are useful for emotion experiments, in part because of their ability to avoid the effects of confounding factors, such as habituation and anticipation (Rosen et al. 1998). In this study, we examined differences in brain activation associated with the two elements of humor, the cognitive element and the affective element, and identified brain areas positively correlated with the rating of funniness using an event-related fMRI paradigm.

\section{Availability and requirements \\ Participants}

Thirteen healthy, right-handed subjects participated in the experiment (mean age 24.8 \pm 3.8 years, range $23-33$ years, four men and nine women). No participant had a history of psychiatric or neurological disorders. The subjects were instructed to watch cartoons without laughing and to not move their heads.

\section{Stimuli}

Five cartoons were used in this study. All images were selected from a pilot study. The cartoons consisted of 7 , $8,9,11$, or 13 scenes. For fMRI study, cartoons were displayed on a monitor and presented to the subject through a $45^{\circ}$ angled mirror positioned above the head coil.

\section{Experimental design}

Stimuli were presented by showing five cartoons selected from a pilot experiment. Stimuli were presented according to an event-related fMRI paradigm with each cartoon being presented for 32 to $46 \mathrm{~s}$. The subjects were instructed to press a button on a keypad immediately if they found the cartoon to be funny. The interval between the cartoons was $4 \mathrm{~s}$. Following the scan, each subject was instructed to assess humor intensity. The subjects were asked to state whether they found the cartoon funny. If they did find it funny, they were asked to rate their perceived humor intensity on a scale of 1 to 7
(1 least funny, 7 most funny). The subjects were then asked to explain the meaning of the cartoons (Figure 1).

\section{Image acquisition}

fMRI experiments were conducted using an ISOL $3 \mathrm{~T}$ Forte scanner (ISOL Technology, Gyeonggi, Korea). During the presentation of visual stimuli, fMRI scanning was performed with the single shot Echo Planar Imaging sequence (repetition time (TR), 2,000 ms; echo time (TE), $28 \mathrm{~ms}$; flip angle, $80^{\circ}$; field of view (FOV), $240 \mathrm{~mm}$; matrix size, $64 \times 64$; slice thickness, $5 \mathrm{~mm}$, no gap; and in-plane resolution, $3.75 \mathrm{~mm}$, three dummy scans). Anatomical T1-weighted images were obtained with a 3-D FLAIR sequence (TR 280, TE 14, FA 60, FOV 240, matrix $256 \times 256$, 4-mm slice thickness).

\section{Data analysis}

Functional images were analyzed using SPM99 (http:// www.fil.ion.ucl.ac.uk/spm/software/spm99/). Data including head motion artifacts that could not be corrected were excluded from analysis. All functional images were realigned with six movement parameters (translation; $x, y, z$ and rotation; pitch, roll, yaw) to correct head motion. Echo-planar imaging (EPI) and T1-weighted images were coregistered and spatially normalized to the Montreal Neurological Institute template (MNI template) using an automated spatial transformation. Normalized images were smoothed using a 7-mm isotropic Gaussian kernel.

Following preprocessing, statistical analysis was performed. fMRI data were analyzed for each subject individually in the context of the general linear model (GLM) and theory of Gaussian random fields. Using subtraction and correlation procedures, activated areas in the brain while observing different pictures were color-coded by T-score.

\section{Results and discussion}

\section{Behavioral results}

After fMRI experiments, all participants rated the intensity of humor. The number of subjects who experienced humor while watching each cartoon was 9 for cartoon \#1, 11 for cartoon \#2, 8 for cartoon \#3, 13 for cartoon \#4, and 8 for cartoon \#5 (Figure 2, upper image). Participants who recognized the cartoons as funny reported an average of 3.5 points for cartoon \#1, 3.2 points for cartoon \#2, 2.5 points for cartoon \#3, 5.2 points for cartoon \#4, and 1.9 points for cartoon \#5, respectively (Figure 2, lower image).

\section{fMRI results}

While viewing humorous scenes, significant activation was observed in the bilateral middle temporal gyrus, left superior temporal gyrus, right fusiform gyrus, right parahippocampal gyrus, left uncus, left inferior frontal gyrus, 


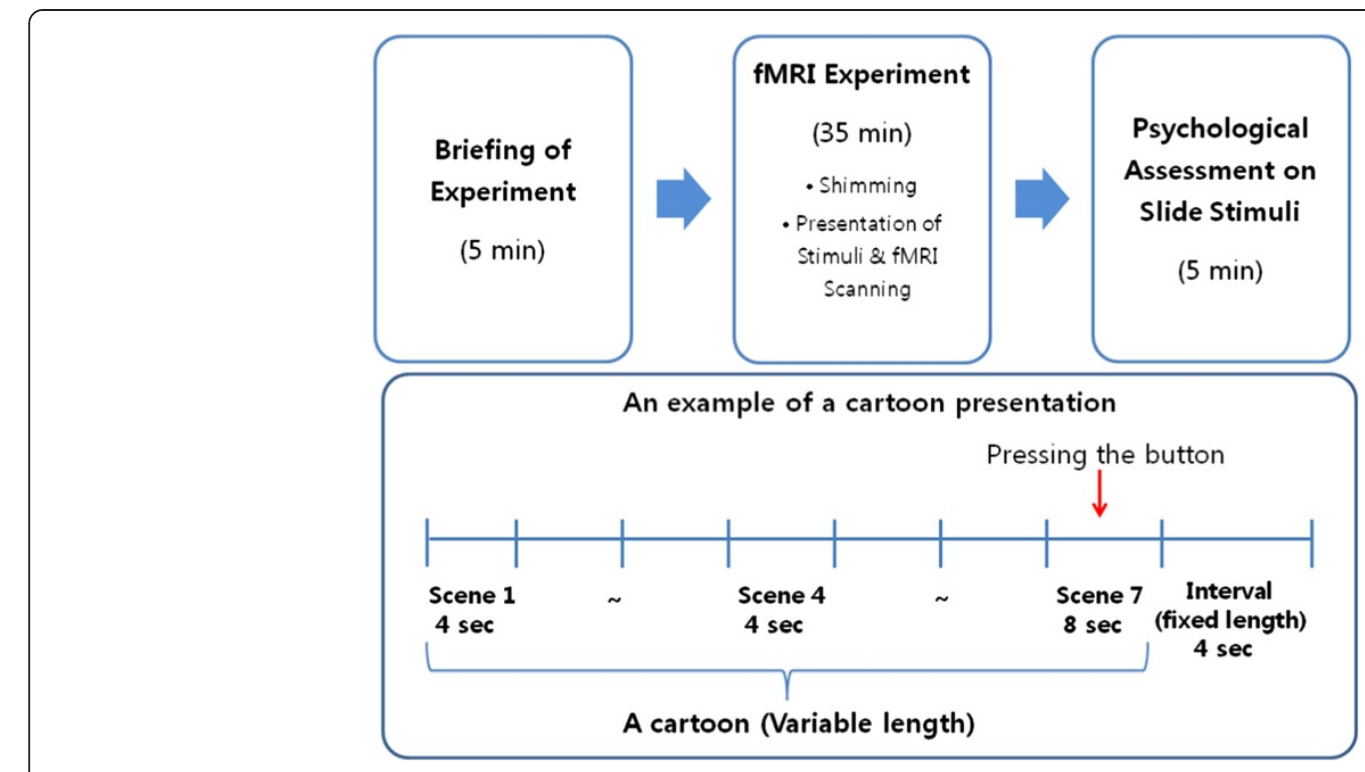

Figure 1 Experimental design. Total experiment time was 45 min, including briefing and psychological assessment.
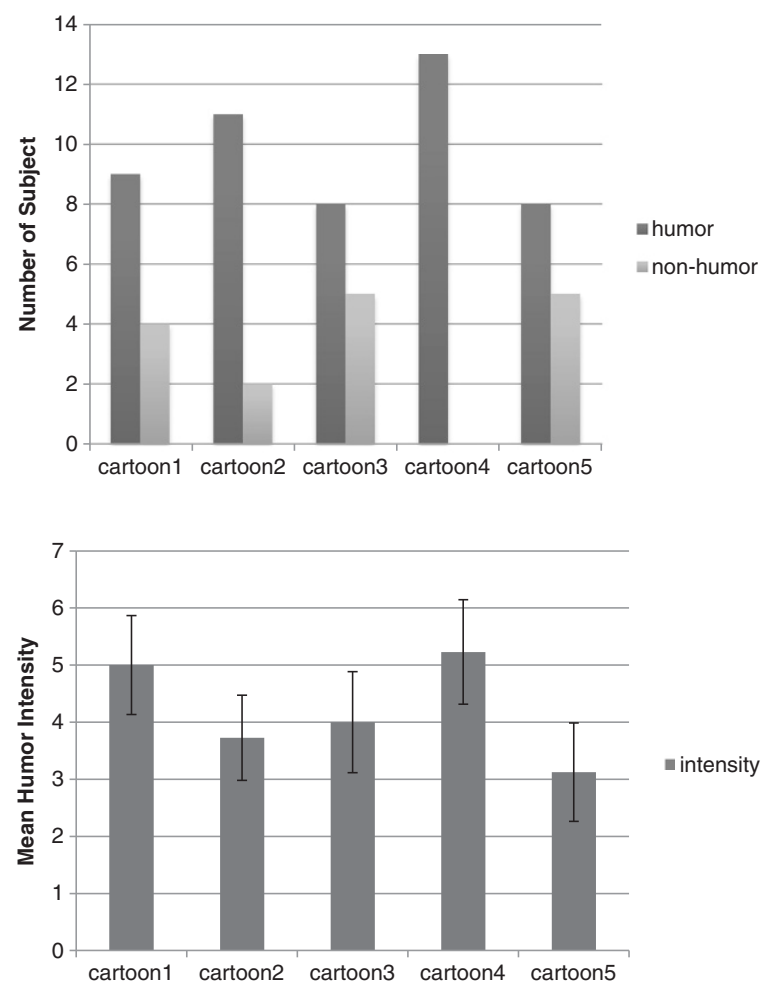

Figure 2 Psychological assessment. Number of subjects who recognized cartoons as humorous or not humorous (upper image). Mean humor intensity of cartoons (lower image). 

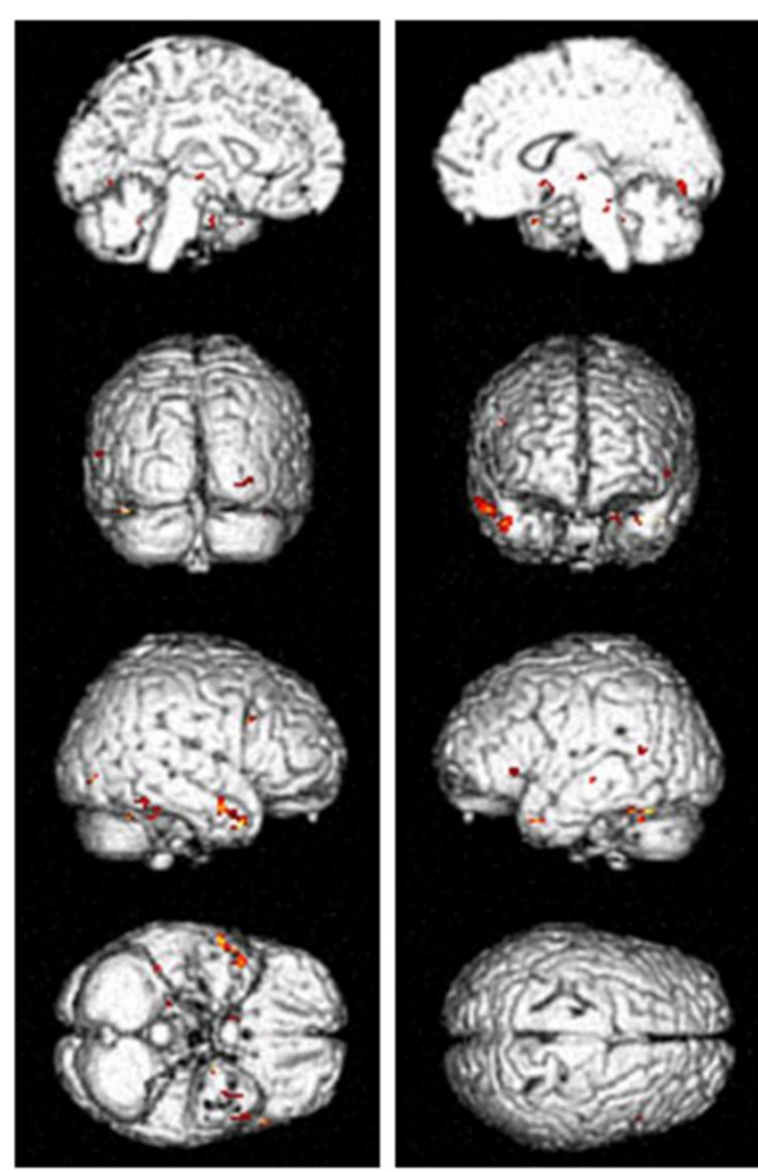

Figure 3 Areas of the brain activated by humorous scenes. Bilateral middle temporal gyrus, left superior temporal gyrus, right fusiform gyrus, right parahippocampal gyrus, left uncus, left inferior frontal gyrus, and right middle frontal gyrus were activated while experiencing humor.
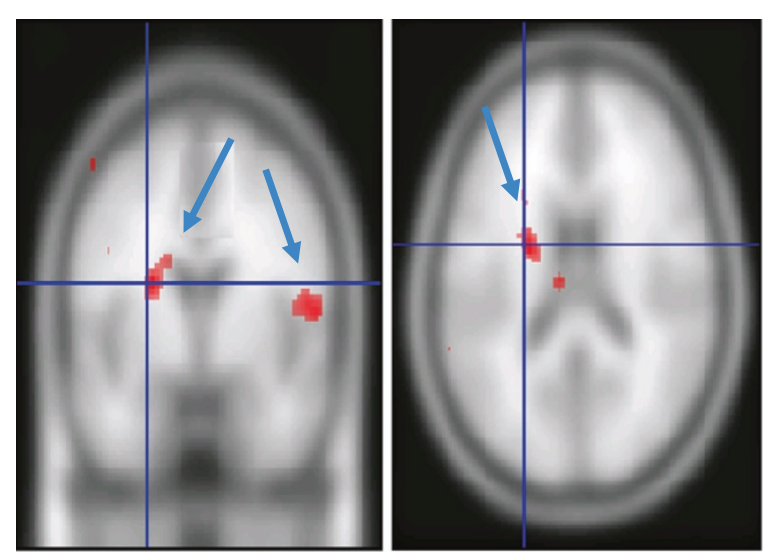

Figure 4 Areas of the brain activated during cartoon scenes with different degrees of humor intensity. Activation in the left nucleus accumbens and right middle temporal gyrus is correlated with humor intensity. 
and right middle frontal gyrus $(p<0.001$, uncorrected; Figure 3).

Humor detection is critically dependent upon resolving incongruities between punch lines and expectations shaped by the storyline (Sul 1972). Consistent with this notion, frontal regions engaged during humor detection have been implicated in language tasks that encourage the retrieval and appraisal of relevant semantic knowledge (Binder et al. 1997, Price et al. 1999). Recent studies have indicated further specialization within the left inferior frontal cortex for reconciling ambiguous semantic content with stored knowledge (Gold and Buckner 2002, Thompson-Schill et al. 1997). Inferior frontal regions may resolve ambiguities between these expectations and punch lines.

Regression analysis was used to examine the association between humor intensity (i.e., the degree of funniness as rated by each subject) and BOLD signal magnitude. This analysis revealed that humor intensity was associated with increased activation in the left nucleus accumbens and right middle temporal gyrus $(\mathrm{p}<0.001$, uncorrected; Figure 4).

Activation of the fusiform gyrus and anterior temporal region caused by electrical stimulation induced laughter accompanied by a feeling of mirth (i.e., positive emotion; Arroyo et al. 1993). The temporal area, including the temporoparietal junction, is involved in the integration of multisensory information and coherence building and inferring knowledge (Ferstl and von Cramon 2002; Goel et al. 1995). Additionally, the temporal lobe may contribute to generating, testing, and correcting internal prediction regarding external sensory events, which is crucial for resolving incongruity in humor processing (Samson et al. 2009). These regions may be involved in the incongruent or surprising (Brownell et al. 1983) elements of a joke and thus may play a pivotal role in the early stages of the humor network.

The nucleus accumbens has been implicated in psychologically and psychopharmacologically driven rewards in various studies (Breiter et al. 2001; Knutson et al. 2001). Activation of the nucleus accumbens elicited by humor converges with findings from fMRI studies across a number of psychologically rewarding tasks, suggesting that this structure is involved in processing a diverse number of stimuli with rewarding characteristics (Aharon et al. 2001; Breiter et al. 2001; Erk et al. 2002; Rilling et al. 2002). Additionally, electrical stimulation of the nucleus accumbens results in laughter and giddiness (Okun et al. 2004). Although we cannot exclude other intervening factors (e.g., novelty), given the results of prior fMRI and physiological studies implicating the nucleus accumbens modulation in self-reported happiness (Knutson et al. 2001) and cocaine/amphetamine-induced euphoria in humans (Brieiter et al. 2001; Drevets et al. 2001), it is reasonable to conclude that nucleus accumbens activation observed in this study reflects the hedonic feeling accompanying humor.

\section{Conclusions}

In this study, using event-related fMRI, we identified areas of the brain that were activated during humor processing. We have presented evidence for differential systems underlying the cognitive and affective processes of humor and the brain region correlated with the degree of humor intensity.

\section{Competing interests}

The authors declare that they have no competing interests.

\section{Authors' contributions}

JN, JWS, JHS, and CC carried out fMRI experiments and analysis. JN and SHK drafted the manuscript. All authors read and approved the final manuscript.

\section{Acknowledgements}

This research has been supported by the Converging Research Center Program funded by the Ministry of Education, Science and Technology (2013K000332), the Korea Science and Engineering Foundation (No. 20120006577), and the Korea Basic Science Institute (T33408).

\section{Author details}

'Division of Magnetic Resonance Research, Korea Basic Science Institute, Ochang, Chungbuk, South Korea. '2Department of Psychology, Brain Research Institute, Chungnam National University, Daejeon, South Korea. ${ }^{3}$ Department of Professional Counseling and Psychotherapy, Graduate School of Health and Complementary Medicine, Wonkwang University, Iksan, Cheonbuk 570-749, South Korea.

Received: 2 December 2013 Accepted: 10 January 2014 Published online: 29 April 2014

\section{References}

Aharon I, Etcoff N, Ariely D, Chabris CF, O'Connor E, Breiter HC (2001) Beautiful faces have variable reward value: $\mathrm{AMRI}$ and behavioral evidence. Neuron 32(3):537-551

Arroyo S, Lesser RP, Gordon B, Uematsu S, Hart H, Schwerdt P, Andeasson K, Fisher RS (1993) Mirth, laughter and gelastic seizures. Brain 116(4):757-780

Binder JR, Frost JA, Hammeke TA, Cox RW, Rao SM, Preieto T (1997) Human brain language areas identified by functional magnetic resonance imaging. J Neurosci 17(1):353-362

Breiter HC, Aharon I, Kahneman D, Dale A, Shizgal P (2001) Functional imaging of neural responses to expectancy and experience of monetary gains and losses. Neuron 30:619-639

Brownell HH, Gardner H (1988) Neuropsychological insights into humour. In: Durant J, Miller J (eds) Laughing matters: a serious look at humour. Longman Scientific and Technia, Harlow, UK

Brownell HH, Michel D, Powelson J, Gardner H (1983) Surprise but not coherence: sensitivity to verbal humor in right-hemisphere patients. Brain Language 18:20-27

Buhler M, Klein SV, Klemen J, Smolka MN (2008) Does erotic stimulus presentation design affect brain activation patterns? Event-related vs. blocked fMRI designs. Behav Brain Funct 4(1):30

Dixon NF (1980) Humor: A cognitive alternative to stress. In Spielberger CD Sarason IG (eds) Anxiety and stress, Hemisphere, Washington DC

Drevets WC, Gautier C, Price JC, Kupfer DJ, Kinahan PE, Grace AA, Price JL, Mathis CA (2001) Amphetamine-induced dopamine release in human ventral striatum correlates with euphoria. Society of Biological Psychiatry 49:81-96

Erk S, Spitzer J, Wunderlich AP, Galley L, Walter H (2002) Cultural objects modulate reward circuitry. Neuroreport 13:2499-2503

Ferstl EC, von Cramon DY (2002) What does the frontomedian cortex contribute to language processing: coherence or theory of mind? Neuroimage 17:1599-1612 Gardner H, Ling PK, Flamm L, Silverman J (1975) Comprehension and appreciation of humorous material following brain damage. Brain 98:399-412 
Gavrilobic J, Lecic-Tosevski D, Dimic S, Pejovic-Milovancevic M, Knezevic G, Priebe S (2003) Coping strategies in civilians during air attacks. Soc Psychiatry Psychiatr Epidemiol 38(3):128-133

Goel V, Grafman JNS, Sadato N, Hallett M (1995) Modeling other minds. Neuroreport 6:1741-1746

Gold BT, Buckner RL (2002) Common prefrontal regions coactivate with dissociable posterior regions during controlled semantic and phonological task. Neuron 35(4):803-812

Josephs O, Turner R, Friston K (1997) Event-related fMRI. Hum Brain Mapp 5:243-248

Knutson B, Adams CM, Fong GW, Hommer D (2001) Anticipation of increasing monetary reward selectively recruits nucleus accumbens. J Neurosci 21:RC159

Martin RA (2001) Humor, laughter, and physical health: methodological issues and research findings. Psychol Bull 127(4):504-519

Mobbs D, Grecius MD, Abdel-Azim E, Menon V, Reiss AL (2003) Humor modulates the mesolimbic reward centers. Neuron 40:1041-1048

Moran JM, Wig GS, Adams RB, Janata P, Kelley WM (2004) Neural correlates of humor detection and appreciation. Neuroimage 21(3):1055-1060

Netzlek JB, Derks P (2001) Use of humor as a copying mechanism, psychological adjustment, and social interaction. Humor International Journal of Humor Research 14:395-413

Neuhoff CC, Scahaefer C (2002) Effects of laughing, smiling, and howling on mood. Psychol Rep 91:1079-1080

Okun MS, Bowers D, Springer U, Shapira NA, Malone D, Rezai AR, Nuttin B, Heilman KM, Morecraft RJ, Rasmussen SA, Greenberg BD, Foote KD, Goodman WK (2004) What's in a smile? Intra-operative observation of contralateral smiles induced by deep brain stimulation. Neurocase 10(4):271-279

Price CJ, Green DW, von Studnitz RA (1999) Functional imaging study of translation and language switching. Brain 122(12):2221-2235

Rilling JK, Gutman DA, Zeh TR, Pagnoni G, Berns GS, Kilts CD (2002) A neural basis for social cooperation. Neuron 35(2):395-405

Rosen BR, Buckner RL, Dale AM (1998) Event-related functional MRl: past, present and future. PNAS Proc Natl Acad Sci U S A 95(3):773-780

Samson AC, Hempelmann CF, Huber O, Zysset S (2009) Neural substrates of incongruity-resolution and nonsense humor. Neuropsychologia 47:1023-1033

Shammi P, Stuss DT (1999) Humour appreciation: a role of the right frontal lobe. Brain 122:657-666

Shammi P, Stuss DT (2003) The effects of normal aging on humor appreciation. J Int Neuropsychol Soc 9:855-863

Suls J (1972) A two-stage model for the appreciation of jokes and cartoons. In: Goldstein PE, McGhee JH (eds) The psychology of humor: theoretical perspectives and empirical issue. Thieme Medical Publishers, New York, pp 81-100

Thompson-Schill SL, E'Esposito M, Aguirre GK, Farah M (1997) Role of left inferior prefrontal cortex in retrieval of semantic knowledge: a reevaluation. PNAS 94(26):14792-14797

Zarahn E, Aguirre G, D'Esposito M (1997) A trial-based experimental design for fMRI. Neuroimage 6:122-138

doi:10.1186/s40543-014-0020-7

Cite this article as: Noh et al:: Neural substrates associated with humor processing. Journal of Analytical Science and Technology 2014 5:20.

\section{Submit your manuscript to a SpringerOpen ${ }^{\circ}$ journal and benefit from:}

- Convenient online submission

- Rigorous peer review

- Immediate publication on acceptance

- Open access: articles freely available online

- High visibility within the field

- Retaining the copyright to your article

Submit your next manuscript at $\gg$ springeropen.com 